\title{
A Modelica model of thermal and mechanical phenomena in bare overhead conductors
}

\author{
Oscar Duarte \\ Universidad Nacional de Colombia, Department of Electrical and Electronics Engineering \\ ogduartev@unal.edu.co \\ Carrera 30, Calle 45, Ed. 453, Of. 202. Bogotá, Colombia
}

\begin{abstract}
A Modelica model of the thermal and mechanical phenomena of bare overhead conductors is presented. The geometry of the catenary is also modeled as an important part of the mechanical phenomena. The model has been compiled and tested using OpenModelica. Some application examples are also presented to illustrate some analysis that can be done with the model.
\end{abstract}

Keywords: overhead conductors, IEEE 738, catenary, sag

\section{Introduction}

Bare overhead conductors are essential in transmission and distribution of large amounts of electrical energy. They are supported by transmission towers and exposed to varying weather conditions. The mechanical behaivor of these suspended cables is affected by thermal processes. Heat transfers change conductor temperature, causing lenght and tension modifications. As a result, the geometry of the catenary described by the cable also changes. It is very important to study this geometric modifications, mainly to avoid electrical failures caused by the violation of security distances.

In this paper we show a Modelica model of the thermal and mechanical phenomena of bare overhead conductors; the geometry of the catenary is also modeled as an important part of the mechanical phenomena. The model has been compiled and tested using OpenModelica ([2], [3]). Some application examples, and the source code are available at the Virtual Academic Services of the National Universty of Colombia ${ }^{1}$.

\footnotetext{
${ }^{1}$ http://www.lab.virtual.unal.edu.co
}

By using Modelica two main advantages have arised:

- The solution of the state change equation is very simple. This is an equation that must be solved by numerical methods. The Modelica model of the equation is done in a natural way, and the algorithms available in OpenModelica are capable to solve it.

- The cargability analysis is immediate. The most common models from overhead conductors use the electrical current in the conductor to compute the conductor temperature for extreme operation conditions and then the mechanical and geometric variables. Cargability analysis is the inverse process: from the mechanical, geometric or thermal limit conditions we must find an electrical current that will cause them. Due to the object-oriented modeling of Modelica, the same model can be used in both directions.

This paper is organized as follows: in section 2 the physcal model is presented in two steps, the thermal model first (section 2.1) and then the mechanical model (section 2.2); in section 3 the Modelica implementation is explained also in two steps (sections 3.1 and 3.2); in section 4 we show some application examples to illustrate the analysis capabilities of the implementation. Conclusions and future work are summarized in section 5 .

\section{Physical model}

\subsection{Thermal model}

The thermal model calculates the conductor temperature for a certain electrical current and weather conditions. The IEEE Standar 738 ([1]) 
defines two different models: one for steady state calculations and another one for transient calculations.

The non-steady heat balance is summarized by equation 1

$$
\frac{d T_{c}}{d t}=\frac{1}{m C_{p}}\left[R I^{2}+q_{s}-q_{c}-q_{r}\right]
$$

Where:

- $T$ is the conductor temperature.

- $m C_{p}$ is the heat capacity of conductor.

- $R$ is the electrical linear resistence of the conductor, which is a function of its temperature.

- $I$ is the current passing through the conductor. The term $R I^{2}$ is the heat gain by Joule effect.

- $q_{s}$ is the heat gain by solar radiation.

- $q_{c}$ is the heat loss by convection.

- $q_{r}$ is the heat loss by radiation.

The standard also stablishes detailed models for every term in equation 1 . The main features of these models are:

$R$ model: electrical linear resistence of conductor is calculated as a function of temperature by a linear interpolation (or extrapolation) of the values at two different temperatures (usually $25^{\circ} \mathrm{C}$ and $75^{\circ} \mathrm{C}$ ). These values are available in manufacturers data sheets.

$m C p$ model: total heat capacity is calculated taking into account the percentage of materials in the conductor (ussualy steel and alluminium).

$q_{s}$ model: the actual heat gain by solar radiation depends on the geographical latitude and altitude in which the conductor is placed, the day of the year, the time of the day, the abosorvity and size of conductor; two atmosphere conditions are considered: clear and industrial.

$q_{c}$ model: natural and forced convection must be calculated. The greatest of the two is used in equation 1 . The wind velocity and direction is considered; air density and viscosity depends on air temperature. Temperature, size and azimuth of conductor are also involved in the model.

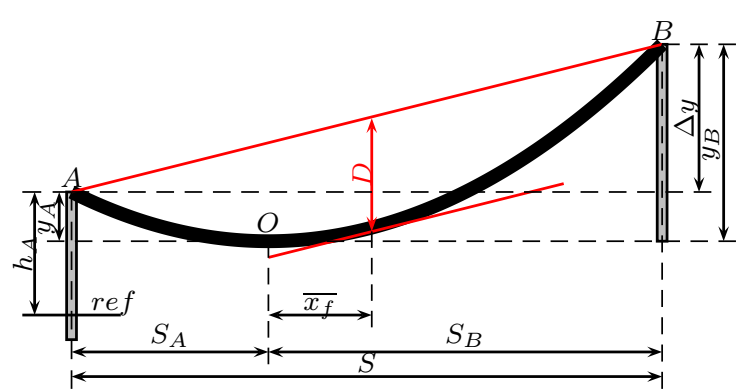

Figure 1: Geometry of the catenary

$q_{r}$ model: radiated heat is calculated using temperature, emmisivity and size of conductor as well as air temperature.

Notice that $T$, which seems to be explicity calculated in 1 is really involved in all the terms. A more accurate equation shoud be:

$$
\frac{d T}{d t}=\frac{1}{m C_{p}}\left[R(T) I^{2}+q_{s}(T)-q_{c}(T)-q_{r}(T)\right]
$$

\subsection{Mechanical model}

Mechanical phenomena in overhead conductors are well known (see for example chapter 14 of [4]). Figure 1 shows an overhead conductor that describes a catenary. It is supported in $A$ y $B$, which are at height $y_{A}$ and $y_{B}$ from the level of the lowest point $(O)$, and with a difference of level $\Delta y . h_{A}$ is the height of $A$ from a reference level. The span (horizontal separation between supports) is $S$. The longitudinal tension is Ten, where as the horizontal tension is $H$. Conductor lenght is $L$, its linear weight is $W$ and is temperature is $T$. The lowest point $O$ is at a horizontal distance $S_{A}$ and $S_{B}$ from supports $A$ and $B$. The length of conductor from the supports $A$ and $B$ to the lowest point $O$ are $L_{A}$ and $L_{B}$.

Sag $D$ is the maximum vertical distance between the imaginary line that connects $A$ and $B$ and the catenary. Sag occurs at the point in which the catenary tangent is the same as the slope of that imaginary line. The horizontal distance between this point and the lowest point $O$ is $\overline{x_{f}}$. 


\subsubsection{Geometric considerations}

The height of the catenary $y(\bar{x})$ from the level of the lowest point $O$ is:

$$
y(\bar{x})=\frac{H}{W} \cosh \left(\frac{W \bar{x}}{H}\right)-\frac{H}{W} ;
$$

Where $\bar{x}$ is the horizontal distance to $O$. Let $x$ be the horizontal distance to $A$. Then we have:

$$
\begin{array}{ccc}
\bar{x} & = & S_{A}-x \\
y(x) & = & \frac{H}{W} \cosh \left(\frac{W\left(S_{A}-x\right)}{H}\right)-\frac{H}{W}
\end{array}
$$

The height of the conductor in $x$ from the reference level is

$$
\begin{gathered}
h(x)=h_{A}-Y_{A}+y(x) \\
h(x)=h_{A}-\frac{H}{W} \cosh \left(\frac{W S_{A}}{H}\right)+ \\
\frac{H}{W} \cosh \left(\frac{W\left(S_{A}-x\right)}{H}\right)
\end{gathered}
$$

The horizontal distance from the lowest point $O$ to the lowest support is $S_{P B}$

$$
S_{P B}=\frac{S_{A}}{2}-\frac{H}{W} \sinh ^{-1}\left\{\frac{\Delta y / 2}{\frac{H}{W} \sinh \left(\frac{W}{H} S_{A} / 2\right)}\right\}
$$

Notice that $S_{P B}$ is equal to $S_{A}$ or $S_{B}$ :

$$
S_{A}=\left\{\begin{array}{cc}
S_{P B} & \text { if } \Delta y \geq 0 \\
A-S_{P B} & \text { if } \Delta y<0
\end{array}\right.
$$

\subsubsection{Computing the sag}

In order to find the sag, first we find the slope $m$ of the imaginary line that connects $A$ and $B$ :

$$
m=\frac{\Delta y}{S}
$$

The first derivative of equation 3 give us the catenary tangent:

$$
\frac{d y}{d \bar{x}}=\sinh \left(\frac{W \bar{x}}{H}\right)
$$

$\overline{x_{f}}$ s the point where the slops equals $m$, so we have:

$$
\overline{x_{f}}=\frac{H}{W} \operatorname{asinh}\left(\frac{\Delta y}{S}\right)
$$

The sag $D$ is the vertical distance from the imaginary line that connects $A$ and $B, y_{r}$, and the catenary $y_{c}$, both in $\overline{x_{f}}$

$$
\begin{array}{ccc}
D & = & y_{r}\left(\overline{x_{f}}\right)-y_{f}\left(\overline{x_{f}}\right) \\
y_{r}\left(\overline{x_{f}}\right) & = & \frac{H}{W} \cosh \left(\frac{W \overline{S_{B}}}{H}\right)-\frac{H}{W}-m\left(S_{b}-x_{f}\right) \\
y_{c}\left(\overline{x_{f}}\right) & = & \frac{H}{W} \cosh \left(\frac{W \overline{x_{f}}}{H}\right)-\frac{H}{W}
\end{array}
$$

\subsubsection{Computing the horizontal tension}

The total lenght $L$ of the cable can be computed from $L=L_{A}+L_{B}$

$L_{A}=\frac{H}{W} \sinh \left(\frac{W S_{A}}{H}\right) \quad L_{B}=\frac{H}{W} \sinh \left(\frac{W S_{B}}{H}\right)$

The cable longitudinal tensión at a distance $S / 2$ from $O$ is

$$
T e n=H \cosh \frac{W S}{2 H}
$$

Suppose two different cable states 0 y 1 . There are now two longitudinal tensions $T e n_{0}$ and $T e n_{1}$, two horizontal tensions $H_{0}$ and $H_{1}$, two temperatures $T_{0}$ and $T_{1}$ and the two lenghts $L_{0}$ and $L_{1}$. Then we have the state change equation:

$$
L_{1}=L_{0}\left[1+a\left(T_{1}-T_{0}\right)+\frac{T e n 1-T e n 0}{E A}\right]
$$

Where $a$ is the coefficient of dilatation, $E$ the elasticity module and $A$ the section area. Notice that the new length must also satisfy equation 13 . Usually numerical methods must be used to satisfy simultaniously equations 13 and 15 .

Assuming that $W$ does not change from state 0 to state 1 , the value of $H_{1}$ is obtained by the solution of

$$
\begin{aligned}
& \frac{H_{1}}{W} \sinh \left(\frac{W S_{A}}{H_{1}}\right)+\frac{H_{1}}{W} \sinh \left(\frac{W\left(S-S_{A}\right)}{H_{1}}\right)= \\
& \left\{\frac{H_{0}}{W} \sinh \left(\frac{W S_{A}}{H_{0}}\right)+\frac{H_{1}}{W} \sinh \left(\frac{W\left(S-S_{A}\right)}{H_{0}}\right)\right\} \\
& {\left[1+a\left(T_{1}-T_{0}\right) \frac{1}{E A}\left[H_{1} \cosh \frac{W S}{2 H_{1}}-H_{0} \cosh \frac{W S}{2 H_{0}}\right]\right]}
\end{aligned}
$$

\section{Modelica implementation}

Conductor and span parameters are stored in separated records named ConductorData and SpanData. Day of the year and time of the day are stored in a third record whose name is TimeData. Tables 1 to 3 summarize the parameters in each record.

\subsection{Thermal model}

14 functions have been defined for the implementation of the thermal model (see table 4). 3 classes have been also designed:

ConvectionHeatFlow: a model similar to the HeatTransfer.Convection model, but whose parameters are driven by the conductor, span and time parameters. 


\begin{tabular}{|l|l|}
\hline declaration & meaning \\
\hline Real D & External diameter \\
\hline Real a & Coefficient of dilatation \\
\hline Real E & Module of elasticity \\
\hline Real W & Linear weight \\
\hline Real A & Cross section area \\
\hline Real C & Linear heat capacity \\
\hline Real R_ref & $\begin{array}{l}\text { Linear electrical re- } \\
\text { sistence }\end{array}$ \\
\hline Real T_ref & $\begin{array}{l}\text { Temperature of refer- } \\
\text { ence }\end{array}$ \\
\hline Real alpha & $\begin{array}{l}\text { Slope of resistance } \\
\text { change }\end{array}$ \\
\hline Real abs $=0.5$ & Absorvity \\
\hline Real emi $=1.0$ & Emissivity \\
\hline
\end{tabular}

Table 1: Parameters in the ConductorData record
SolarHeatFlow: a model similar to the HeatTransfer.PrescribedHeatFlow model, but whose value is driven by sun and span position.

\section{Stand AloneHeatingResistor: a}

model similar to the Electrical.Analog.Basic.HeatingResistor model, that also computes the heat gain by Joule effect for a certain electrical current.

Conductor: it is a Heat Capacitor with a temperature signal port.

\subsection{Mechanical and geometrical model}

Mechanical and geometrical model is implemented by 4 functions (table 5) and 4 main classes:

CatenaryStateChange: this class is the implementation of the state change equations 15 and 16. (See File 1). This class is perhaps, the most important of the mechanical model. Here we stablish that the state equation must also satisfy the new length condition of 13. In order to help a fast solution of the state change equations, a starting point for $\alpha=H / W$ can be set. We suggest to use $300^{2}$.

Catenary: it is a partial class that joins the thermal, mechanical and geometrical models (see 2 ). In one hand it implements equation 1 as a Conductor (i.e. a heat capacitor) whose heat port has attached models for the heat flows (joule effect $q_{J}$, solar radiation $q_{s}$, convection $q_{c}$ and radiation $q_{r}$ ); air temperature $T_{a}$ is included as a prescribed temperature. In the other hand it has also a component of the CatenaryStateChange class; the temperature of the Conductor is used as an input for the State Change analysys, whose main output is the sag $D$ calculation. In order to use this class, a derived class must be designed, so the electrical current $I$ is defined. See File 3.

ElectricalCatenary: it is a derived class from Catenary class, in which a electrical current signal is attached to the conductor

\footnotetext{
${ }^{2}$ As an example, in the simulation shown in section 4.1 the numerical methods have found $\alpha=394.7$ for $t=0$
} 


\begin{tabular}{|c|c|}
\hline function & compute: \\
\hline AirConductivity & $\begin{array}{l}\text { thermal air conduc- } \\
\text { tivity as a function of } \\
\text { film air temperature }\end{array}$ \\
\hline AirDensity & $\begin{array}{l}\text { air density as a func- } \\
\text { tion of altitude and } \\
\text { film air temperature }\end{array}$ \\
\hline AirViscosity & $\begin{array}{l}\text { air viscosity as a } \\
\text { function of film air } \\
\text { temperature }\end{array}$ \\
\hline AngleFactor & $\begin{array}{l}\text { correction factor } \\
\text { for convection heat } \\
\text { losses as a function } \\
\text { of the angle be- } \\
\text { tween the wind and } \\
\text { conductor }\end{array}$ \\
\hline Asinh & $\operatorname{asinh}(x)$ \\
\hline Convectionflow & $\begin{array}{l}\text { convection heat } \\
\text { losses }\end{array}$ \\
\hline ForcedConvectionHigh & $\begin{array}{l}\text { forced convection } \\
\text { heat losses for high } \\
\text { wind speeds }\end{array}$ \\
\hline ForcedConvectionLow & $\begin{array}{l}\text { forced convection } \\
\text { heat losses for low } \\
\text { wind speeds }\end{array}$ \\
\hline ForcedConvection & $\begin{array}{l}\text { forced convection } \\
\text { heat losses for any } \\
\text { wind speed }\end{array}$ \\
\hline NaturalConvection & $\begin{array}{l}\text { natural convection } \\
\text { heat losses }\end{array}$ \\
\hline FilmTemperature & $\begin{array}{l}\text { film air temperature } \\
\text { as a function of air } \\
\text { and conductor tem- } \\
\text { peratures }\end{array}$ \\
\hline SolarAltitude & $\begin{array}{l}\text { sun Altitude as a } \\
\text { function of latidude, } \\
\text { day of the year and } \\
\text { time of the day }\end{array}$ \\
\hline SolarAzimuth & $\begin{array}{l}\text { sun azimuth as a } \\
\text { function of latidude, } \\
\text { day of the year and } \\
\text { time of the day }\end{array}$ \\
\hline SolarFlux & $\begin{array}{l}\text { solar heat gain as a } \\
\text { functin of altitude, } \\
\text { solar altitude, sun } \\
\text { and conductor az- } \\
\text { imuths and type of } \\
\text { atmosphere }\end{array}$ \\
\hline
\end{tabular}

Table 4: Functions for the thermal model

\begin{tabular}{|l|l|}
\hline function & compute: \\
\hline CatenaryLenght & equation 13 \\
\hline CatenarySag & equation 12 \\
\hline CatenarySa & equation 8 \\
\hline CatenaryXbar & equation 3 \\
\hline
\end{tabular}

Table 5: Functions for the mechanical and geometrical model

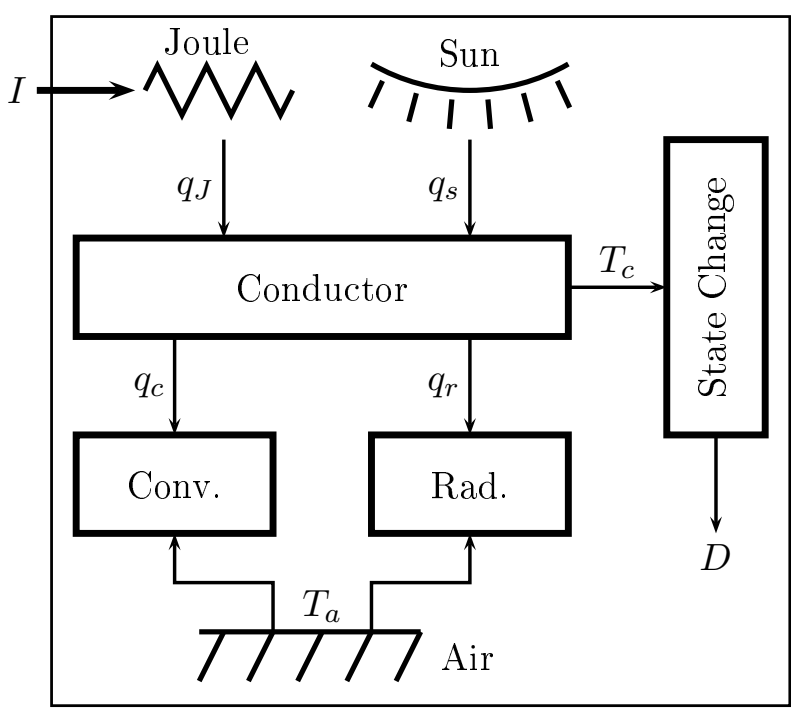

Figure 2: Catenary model

StandAloneCatenary: it is a derived class from Catenary class, the electrical current value is a Real, without attaching any signal to the conductor. In File 2 we show how to use this class for some specific simulation conditions.

\section{System analysis and examples}

In this section we illustrate the analysis capabilities of the model. To do it, we have applied the model to a real span of a $230 \mathrm{KV}$ distribution system in Bogotá, Colombia. The model was implemented using OpenModelica. As a part of a previous cargability study the span was modeled in detail ([5]). Most of the parameters were available (see table 6), however some experiments were conducted in order to identify the actual values of the following parameters:

- Emissivity.

- Absorvity.

- Conductor length in the state of reference. 


\begin{tabular}{|c|c|}
\hline \multicolumn{2}{|c|}{ Span parameters } \\
\hline Conductor & Peacock \\
\hline Altitude & $2600 \mathrm{msnm}$ \\
\hline Latitude & $4.779423^{\circ}$ Norte \\
\hline Azimuth & $76.14^{\circ}$ \\
\hline $\begin{array}{l}\text { Horizontal distance be- } \\
\text { tween supports }\end{array}$ & $82.31 \mathrm{~m}$ \\
\hline $\begin{array}{l}\text { Difference of levels be- } \\
\text { tween supports }\end{array}$ & $0.4 ; m$ \\
\hline $\begin{array}{l}\text { Nominal longitudinal } \\
\text { tension }\end{array}$ & $2970 K g f$ \\
\hline \multicolumn{2}{|c|}{ Conductor parameters } \\
\hline External diameter & $24.2 \mathrm{~mm}$ \\
\hline $\begin{array}{lll}\text { Linear } & \text { resistence } & \text { at } \\
25^{\circ} \mathrm{C} & & \end{array}$ & $9.7 * 10^{-5} \mathrm{ohm} / \mathrm{m}$ \\
\hline $\begin{array}{llr}\text { Linear resistence at } \\
75^{\circ} \mathrm{C} & & \\
\end{array}$ & $0.000116 \mathrm{ohm} / \mathrm{m}$ \\
\hline Aluminium mass & $0.79716 \mathrm{Kg} / \mathrm{m}$ \\
\hline Steel mass & $0.31227 \mathrm{Kg} / \mathrm{m}$ \\
\hline Linear weigth & $1.16 \mathrm{Kg} / \mathrm{m}$ \\
\hline $\begin{array}{l}\text { Nominal elasticity mod- } \\
\text { ule }\end{array}$ & $\begin{array}{l}0.7530 \\
10^{6} \mathrm{KG} / \mathrm{cm}^{2}\end{array}$ \\
\hline $\begin{array}{l}\text { Nominal coefficient of } \\
\text { dilatation }\end{array}$ & $19.73 * 10^{-6} 1 /{ }^{\circ} \mathrm{C}$ \\
\hline Cross section area & $3,4638 \mathrm{~cm}^{2}$ \\
\hline
\end{tabular}

Table 6: Parameters for the examples

\subsection{Heating analysis}

First we study the change of conductor temperature for specific operation conditions. In this example we vary just two operation conditions through a 24 hour period: electrical current $I$ (Figure 3) and air temperature $T_{a}$ (Figure 4). These operation conditions may be considered as inputs for the present analysis where as the conductor temperature $T$ shown in figure 5 is computed as an output.

\subsection{Cargability analysis}

Cargability analysis is the study of the maximum amount of electrical current that can pass through the conductor without getting a limit condition. In this example we state the limit condition as a conductor temperature of $75^{\circ} \mathrm{C}$ and suppose the air temperature profile shown in figure 6. Cargability has been drawn in figure 7 . Notice that the electrical current now is considered as an output of the model. The simulated model is shown in
File 4.

\subsection{Sag analysis}

We now analize the relation between Sag and three variables: electrical current $I$, air temperature $T_{a}$ and conductor temperature $T$. We use the current profile of figure 3 and the air temperature profile of figure 6 , and plot the sag $D$ against the three variables (figures 8 to 10 ).

Notice that neither $I$ nor $T_{a}$ can explain alone the sag $D$. As the 24 hour cycles of $I$ and $T_{a}$ have different shapes (figures 3 and 6 ), and because of the nonlinear dynamic nature of the phenomena, during the 24 hour the same electrical current can occur two or more times with different sags.

Also notice that inspite the non linearities present in the equations of section 2.2 , the relation between conductor temperature $T$ and $\operatorname{sag} D$ is almost linear. This is why some facilities are now measuring the conductor temperature online, and not just the electrical current, in order to study the real online cargability.

\subsection{Catenary analysis}

We can also draw the catenary. To do that we use the dummy variable $x=S t$ using $\dot{x}=S$, and use equation 3 in a simulation with stop time of $1 s$. An example is shown in figure 11

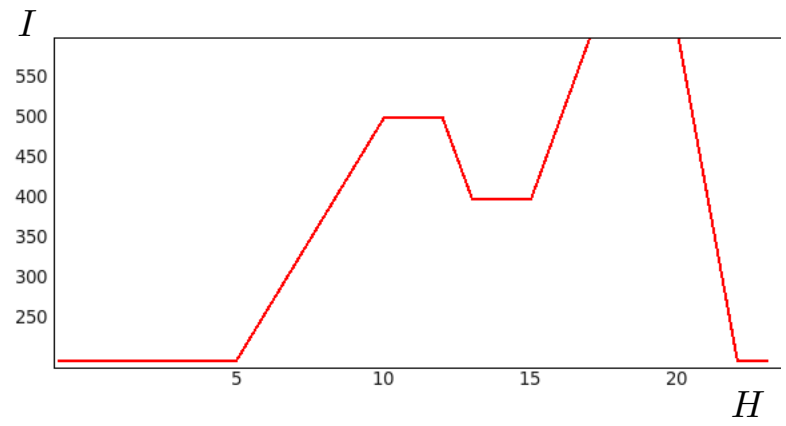

Figure 3: Example 1. Electrical current $I$ (A) vs Time of the day $H(\mathrm{~h})$

\section{Conclusions}

A model for bare overhead conductors has been presented. It combines thermal, mechanical and geometrical phenomena. The core of the thermal model is a heat capacitor whose parameters and 
$T a$

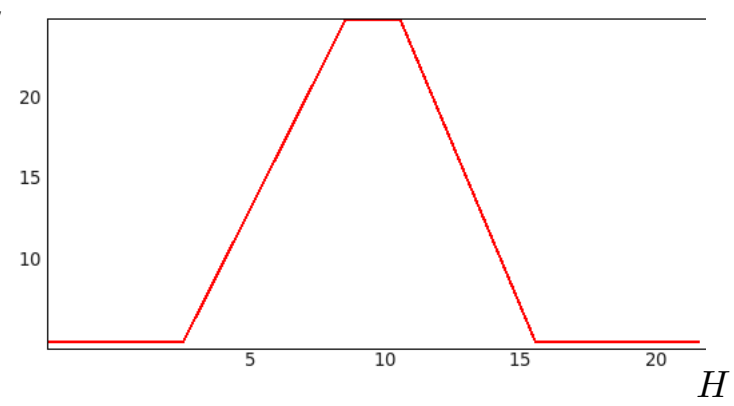

Figure 4: Example 1. Air temperature $\mathrm{Ta}\left({ }^{\circ} \mathrm{C}\right)$ vs Time of the day $H(\mathrm{~h})$

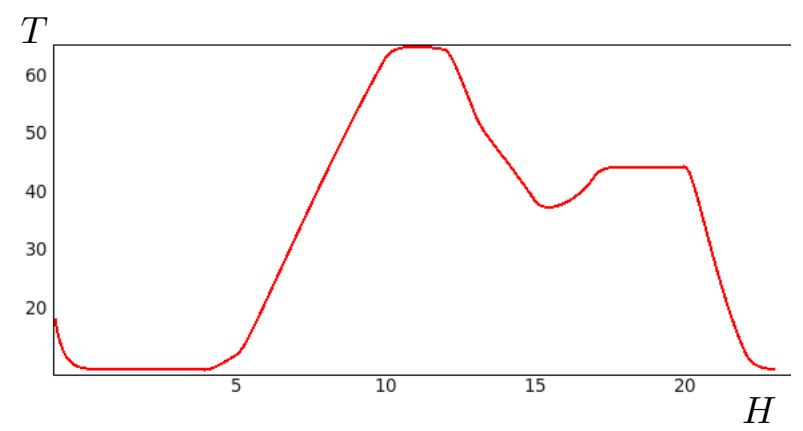

Figure 5: Example 1. Conductor temperature $T$ $\left({ }^{\circ} \mathrm{C}\right)$ vs Time of the day $H(\mathrm{~h})$

inputs are driven by operation conditions as stated by the IEEE 738 standard. The mechanical model solves the state change equation for the conductor temperature of the thermal model and calculates the catenary geometry.

By using Modelica, two advantages have been found, that are clear examples of the objectoriented modeling advantages:

- The solution of the state equation is very simple. We just need to write two conditions for the conductor lenght. OpenModelica has generated the source code that we need in order to solve the equation.

- Cargability analysis is also simple. IEEE 738 standard give us a way to compute conductor temperature from an electrical current for specific operation conditions. However, the inverse problem (compute the current for a conductor temperature) is just solved for steady state in the standard. Using Modelica and OpenModelica the cargability problem is solved without any new equation.
$T a$

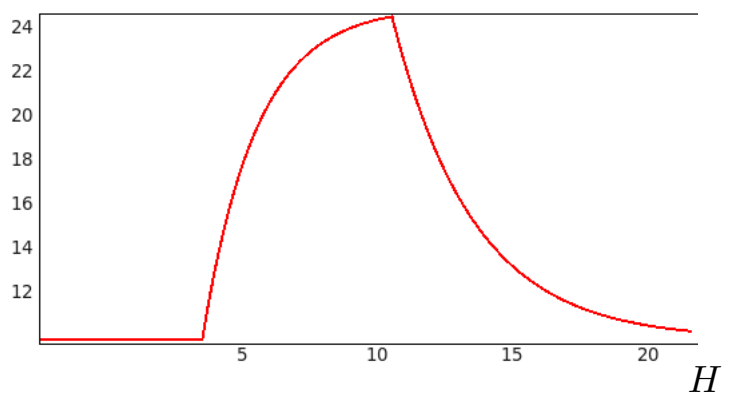

Figure 6: Example 2. Air temperature $\mathrm{Ta}\left({ }^{\circ} \mathrm{C}\right)$ vs Time of the day $H(\mathrm{~h})$

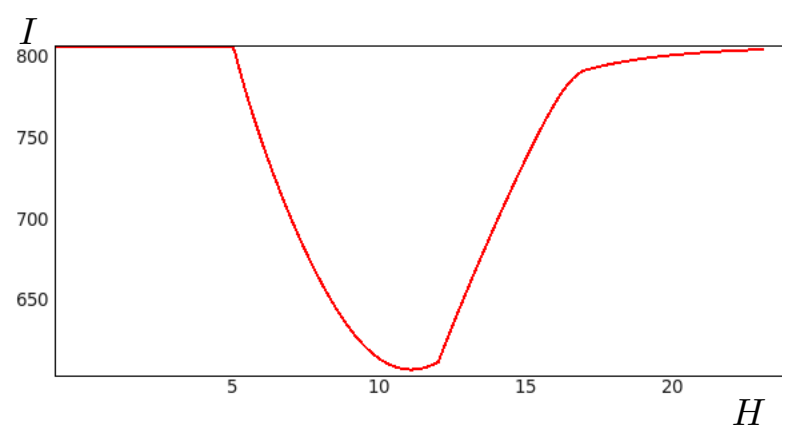

Figure 7: Example 2. Maximimum electrical current $I$ (A) vs Time of the day $H(\mathrm{~h})$

We plan to create a Modelica library for bare overhead conductors in the short term. The library will include the parameters for the most common comercial conductors, and more analysis functionalities.

\section{References}

[1] IEEE Power Engineering Society, IEEE Standard for Calculating the CurrentTemperature of Bare Overhead Conductors IEEE Std 738-2006. January 2007.

[2] OpenModelica, http://www.openmodelica.org/ last visit: november 22, 2010.

[3] Peter Fritzson, Peter Aronsson, Adrian Pop, Håkan Lundvall, Kaj Nyström, Levon Saldamli, David Broman, Anders Sandholm: OpenModelica - A Free Open-Source Environment for System Modeling, Simulation, and Teaching, IEEE International Symposium on Computer-Aided Control Systems Design, October 4-6, 2006, Munich, Germany 


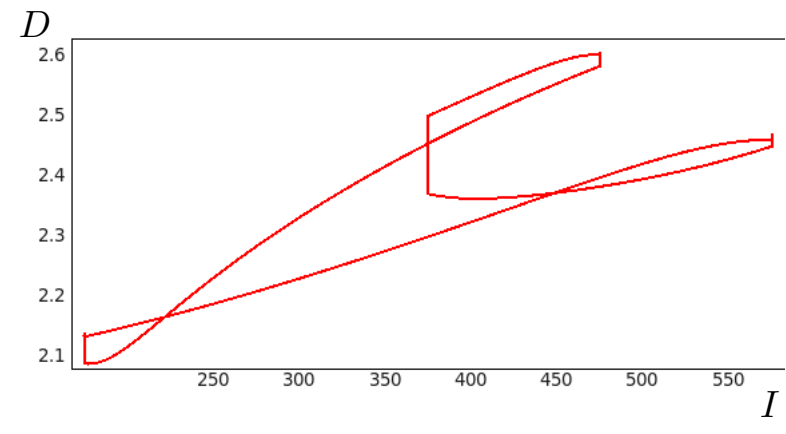

Figure 8: Example 3. Sag $D(\mathrm{~m})$ vs Electrical current $I(\mathrm{~A})$

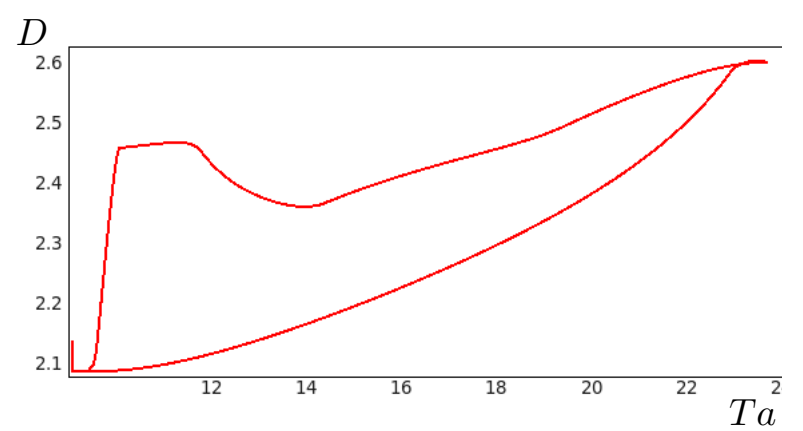

Figure 9: Example 3. Sag $D(\mathrm{~m})$ vs Air temperature $T\left({ }^{\circ} \mathrm{C}\right)$

[4] Donald G. Fink, H. Wayne Beaty. Standard Handbook for Electrical Engineers. McGrawHill Professional

[5] Oscar Duarte, Jaime Alemán, René Soto, Estrella Parra, Francisco Amórtegui, Wilson Aldana. Identificación de parámetros y estudio de cargabilidad en algunas Líneas de Transmisión de Codensa. Technical report. 2009.

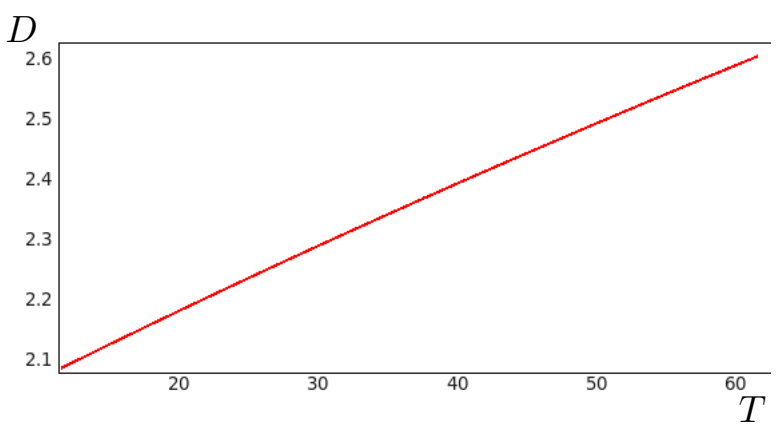

Figure 10: Example 3. Sag $D(\mathrm{~m})$ vs Conductor temperature $T\left({ }^{\circ} \mathrm{C}\right)$

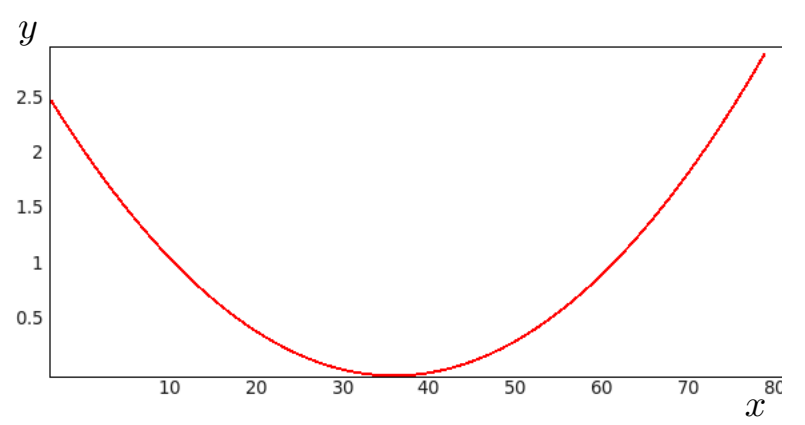

Figure 11: Example 4. Shape of the catenary. Height $y(\mathrm{~m})$ vs Horizontal distance $x(\mathrm{~m})$

File 1: CatenaryStateChange.mo

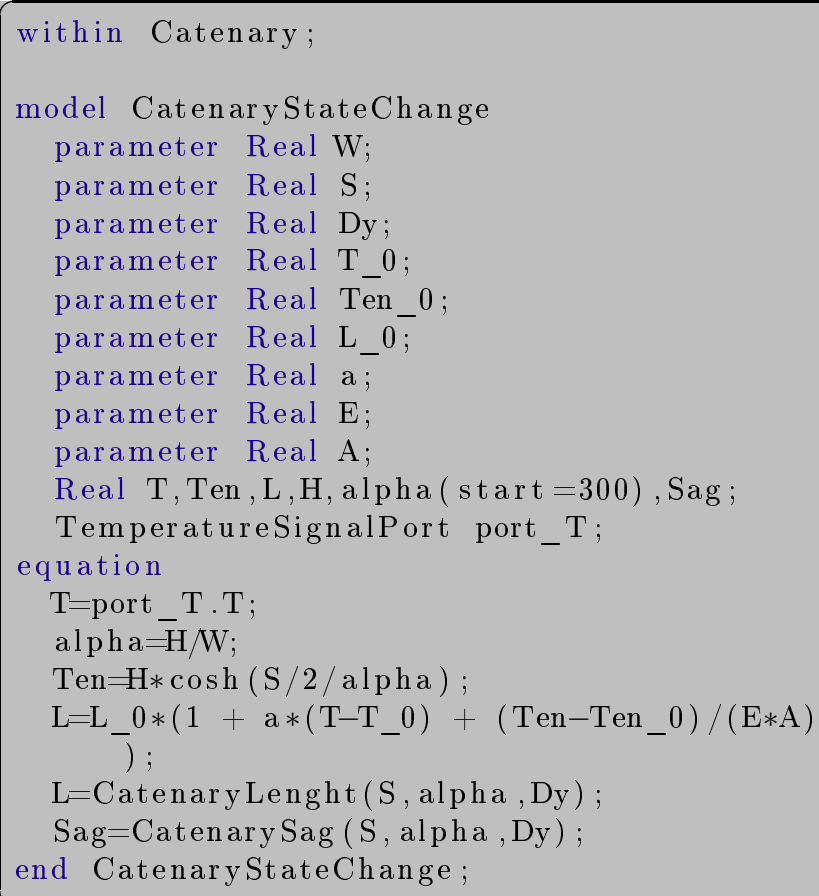


File 3: Catenary.mo

File 2: MyStandAloneLine.mo

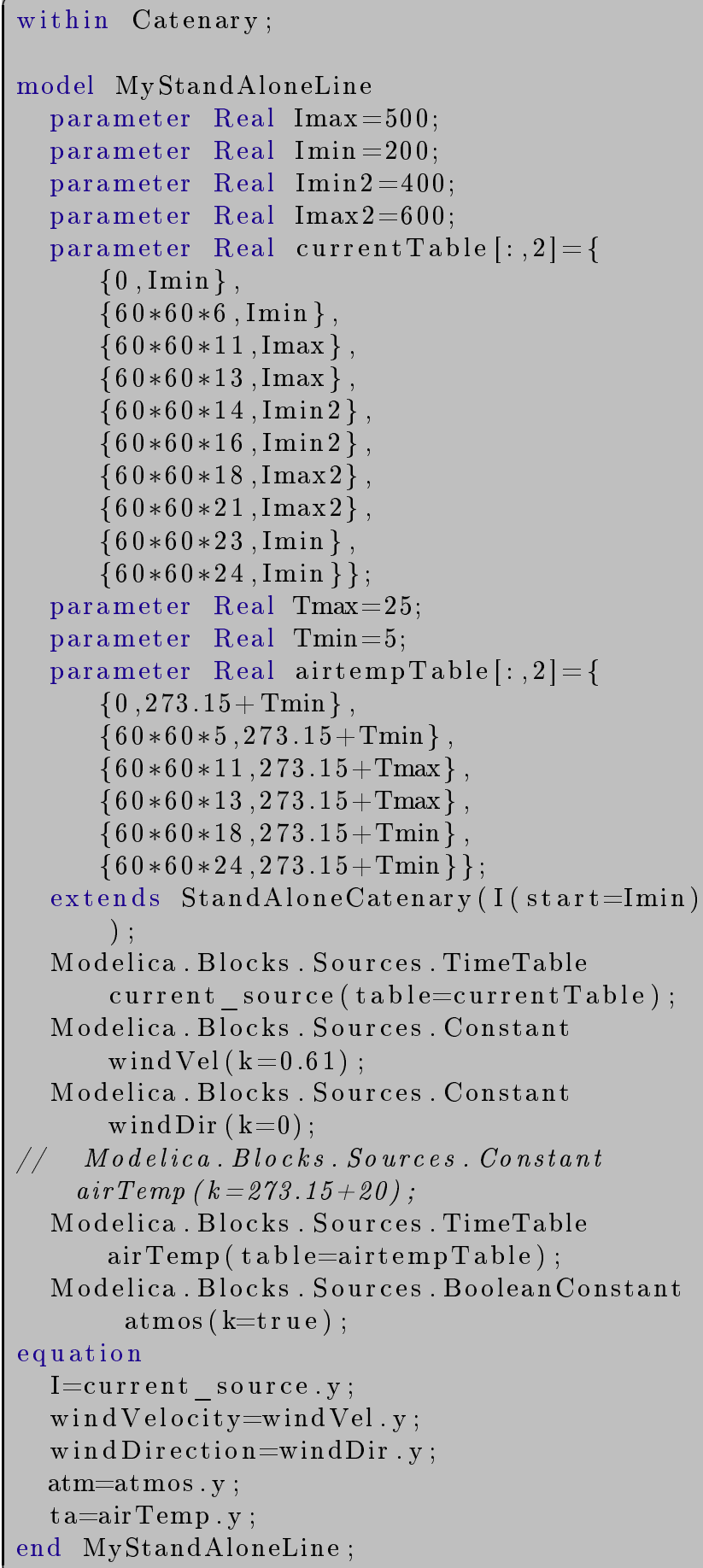

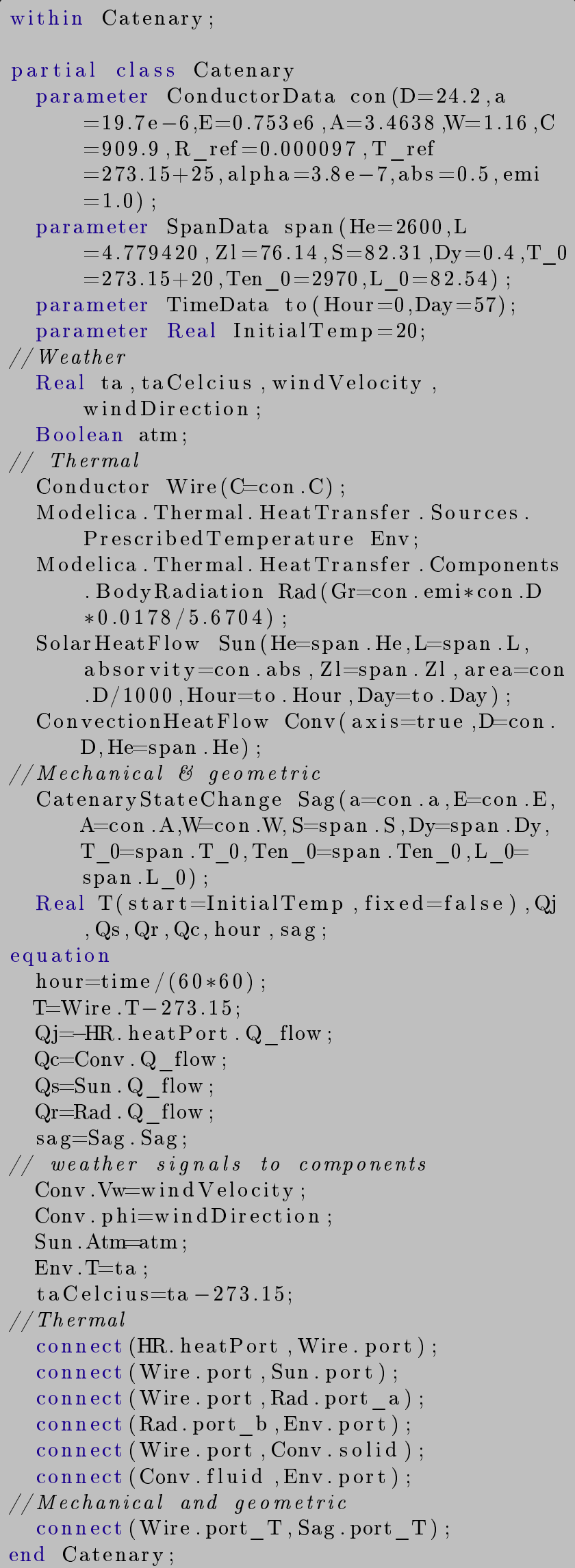

SolarHeatFlow Sun $(\mathrm{He}=\operatorname{span} . \mathrm{He}, \mathrm{L}=\operatorname{span} . \mathrm{L}$, absorvity $=$ con. abs,$Z 1=$ span.$Z 1$, area $=$ con .D $/ 1000$, Hour $=$ to. Hour , Day=to . Day ) ;

Convection HeatFlow Conv ( axis $=\operatorname{true}, \mathrm{D}=\mathrm{con}$. $\mathrm{D}, \mathrm{He}=\mathrm{span} . \mathrm{He})$;

$/ /$ Mechanical \& geometric

CatenaryStateChange $\mathrm{Sag}(\mathrm{a}=\mathrm{con} . \mathrm{a}, \mathrm{E}=\mathrm{con} . \mathrm{E}$, $\mathrm{A}=\mathrm{con} . \mathrm{A}, \mathrm{W}=\mathrm{con} . \mathrm{W}, \mathrm{S}=\operatorname{span} . \mathrm{S}, \mathrm{Dy}=\operatorname{span} . \mathrm{Dy}$, T_0 $\operatorname{span} . T_{-} 0$, Ten_0 $=\operatorname{span}$. Ten_0, L_0 span.L_0);

Real $\mathrm{T}$ ( start=InitialTemp, fixed=false ), Qj equation , Qs, Qr, Qc, hour, sag ;

hour $=$ time $/(60 * 60)$;

$\mathrm{T}=$ Wire $. \mathrm{T}-273.15$;

$\mathrm{Qj}=-\mathrm{HR}$. heatPort. Q_flow;

$\mathrm{Qc}=$ Conv. Q_flow;

Qs=Sun. Q flow;

$\mathrm{Qr}=\operatorname{Rad} . \mathrm{Q}_{-}$flow ;

sag=Sag. Sag;

// weather signals to components

Conv. Vw=wind Velocity;

Conv $\cdot$ phi=windDirection ;

Sun. Atm $=$ atm ;

Env. T=ta ;

t a Celcius=ta -273.15 ;

//Thermal

connect (HR. heatPort, Wire . port);

connect (Wire.port, Sun . port);

connect (Wire.port, Rad.port_a);

connect (Rad.port_b, Env. port);

connect (Wire.port, Conv. solid);

connect (Conv. fluid , Env. port);

$/ /$ Mechanical and geometric

connect (Wire.port_T, Sag.port_T) ;

end Catenary; 
File 4: Cargability.mo

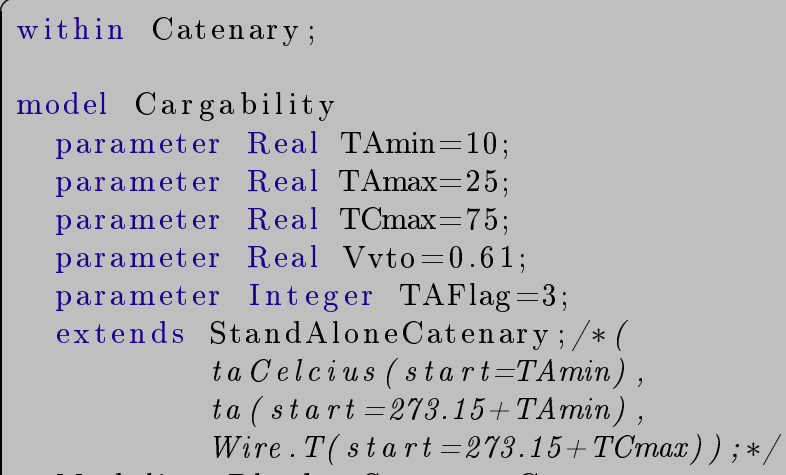

Modelica. Blocks. Sources. Constant temperature_source $(\mathrm{k}=273.15+\mathrm{TCmax})$;

Temparature of conductor known / Ex. of

Modelica. Blocks. Sources. Constant windVel ( $k=$ Vvto);

Modelica. Blocks. Sources. Constant windDir $(k=0)$;

Modelica. Blocks. Sources. Trapezoid airTemp1 ( offset $=273.15+$ TAmin, amplitude $=$ TAmax-TAmin, start Time $=60 * 60 * 6$, rising $=60 * 60 * 5$, width $=60 * 60 * 2$, falling $=60 * 60 * 5$, period $=60 * 60 * 24)$;

Modelica. Blocks. Sources. Sine airTemp2 $($ offset $=273.15+($ $\mathrm{TAmax}+\mathrm{TAmin}) / 2$, a m plit u de $=(\mathrm{TAmax}-\mathrm{TAmin}$ )$/ 2$, freqHz $=1 /(60 * 60 * 24)$, phase $=-$ Modelica. Constants . pi $/ 2)$;

Modelica. Blocks. Sources. Exponentials airTemp3 $($ offset $=273.15+$ TAmin, outMax $=$ TAmax-TAmin, start Time $=60 * 60 * 6$, riseTime $=60 * 60 * 7$, rise TimeConst $=60 * 60 * 2$, fall TimeConst $=60 * 60 * 3)$;

Modelica. Blocks. Sources. BooleanConstant $\operatorname{atmos}(\mathrm{k}=\mathrm{true})$;

\section{equation}

Wire. $\mathrm{T}=$ temperature source. $\mathrm{y}$;

windVelocity $=$ windVel.$y$;

windDirection $=$ windDir $\cdot y$;

atm $=\operatorname{atmos} . y$;

if TAFlag $=1$ then

$\mathrm{ta}=\operatorname{airTemp} 1 \cdot \mathrm{y}$;

elseif TAFlag $=2$ then

$\mathrm{ta}=\operatorname{airTemp} 2 \cdot \mathrm{y}$;

elseif TAFlag $==3$ then

$\mathrm{ta}=\operatorname{airTemp} 3 . \mathrm{y}$;

end if;

end Cargability ;
File 5: SagAnalysis.mo

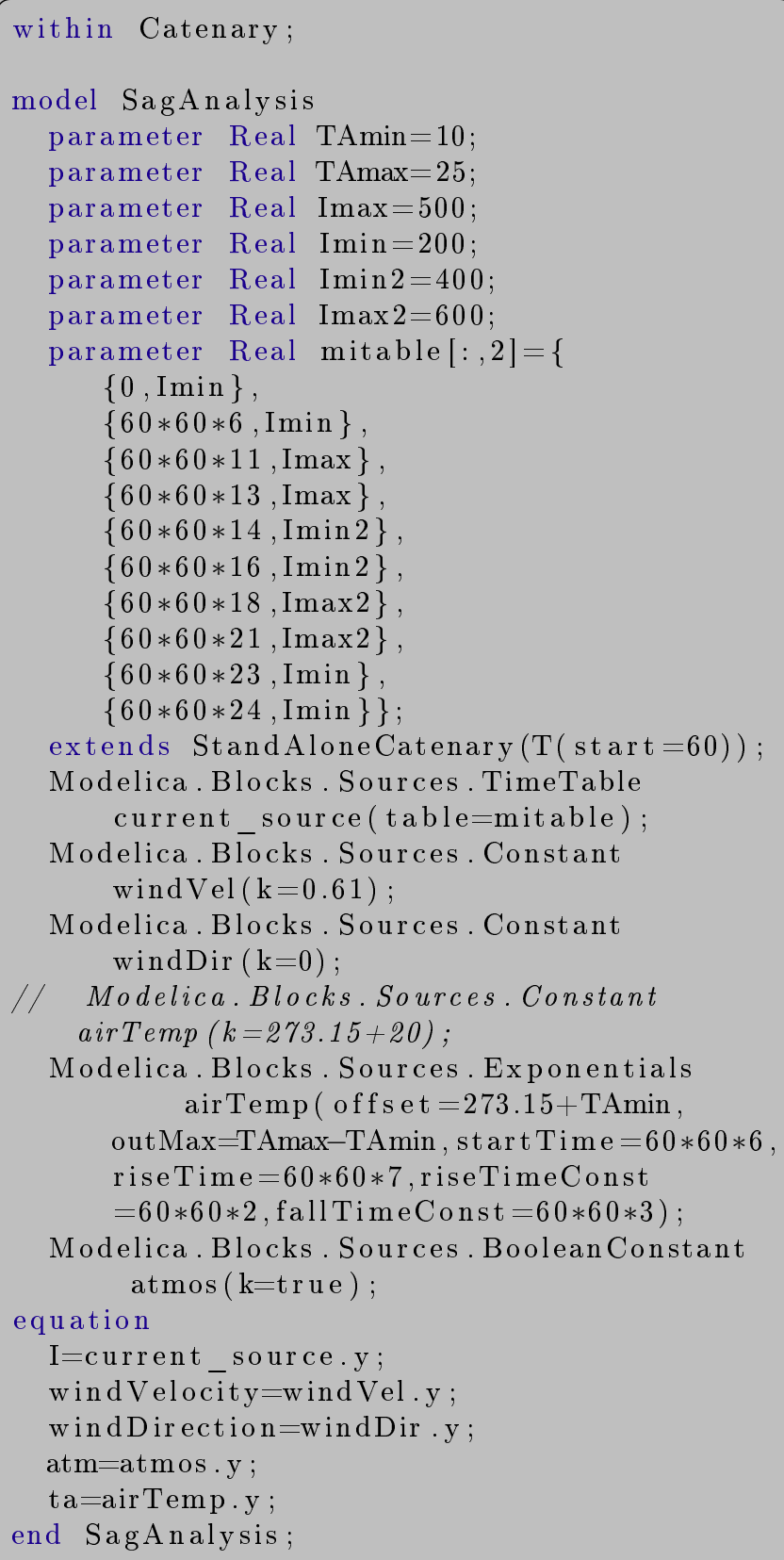

